\title{
Understanding The Structure And Composition of Recalcitrant Oligosaccharides In Ammonia Treated Lignocellulosic Biomass Hydrolysate Using High- Throughput Biotin- Based Glycome Profiling And Mass Spectrometry.
}

Saisi Xue

Michigan State University

Sivakumar Pattathil

Mascoma LLC

\section{Leonardo Costa Sousa}

Michigan State University

\section{Bryan Ubanwa}

University of Houston

\section{Bruce Dale}

Michigan State University
A. Daniel Jones
Michigan State University
Venkatesh Balan ( $\sim$ vbalan@uh.edu )
University of Houston

\section{Research Article}

Keywords: Lignocellulosic biomass, recalcitrant oligosaccharides, glycome profiling, biotinylating, MALDITOF-MS

Posted Date: June 7th, 2021

DOI: https://doi.org/10.21203/rs.3.rs-465723/v1

License: (9) This work is licensed under a Creative Commons Attribution 4.0 International License. Read Full License 


\section{Abstract}

Novel Immunological and Mass Spectrometry Methods for Comprehensive Analysis of Recalcitrant Oligosaccharides in AFEX Pretreated Corn Stover Lignocellulosic biomass is a sustainable alternative to fossil fuel and is extensively used for developing bio-based technologies to produce products such as food, feed, fuel, and chemicals. The key to these technologies is to develop cost competitive processes to convert complex carbohydrates present in plant cell wall to simple sugars such as glucose, xylose and arabinose. Since lignocellulosic biomass is highly recalcitrant, it must undergo a combination of thermochemical treatment such as Ammonia Fiber Expansion (AFEX), dilute acid (DA), lonic Liquid (IL) and biological treatment such as enzyme hydrolysis and microbial fermentation to produce desired products. However, when using commercial fungal enzymes during hydrolysis, only $75-85 \%$ of the soluble sugars generated are monomeric sugars, while the remaining $15-25 \%$ are soluble recalcitrant oligosaccharides that cannot be easily utilized by microorganisms. Previously, we successfully separated and purified the soluble recalcitrant oligosaccharides using a combination of charcoal and celite-based separation followed by size exclusion chromatography and studies their inhibitory properties on enzymes. We discovered that the oligosaccharides with higher degree of polymerization (DP) containing methylated uronic acid substitutions were more recalcitrant towards commercial enzyme mixtures than lower DP and neutral oligosaccharides. Here, we report the use of several complementary techniques that include glycome profiling using plant biomass glycan specific monoclonal antibodies (mAbs) to characterize sugar linkages in plant cell walls and enzymatic hydrolysate, matrix-assisted laser desorption ionization time-of-flight mass spectrometry (MALDI-TOF-MS) using structurally-informative diagnostic peaks offered by negative ion post-secondary decay spectra, gas chromatography followed by mass spectrometry (GC-MS) to characterize oligosaccharide sugar linkages with and without derivatization. Since oligosaccharides (DP 4-20) are small, it is challenging to immobilize these molecules for mAbs binding and characterization. To overcome this problem, we have developed a new biotin-coupling based oligosaccharide immobilization method that successfully tagged most of the low DP soluble oligosaccharides on to a micro-plate surface followed by specific linkage analysis using mAbs in a high-throughput system. This new approach will help develop more advanced versions of future high throughput glycome profiling methods that can be used to separate and characterize oligosaccharides present in biomarkers for diagnostic applications.

\section{Introduction}

Lignocellulosic biomass comprised of agricultural, forest, herbaceous and woody materials are potential feedstocks for producing biobased products including food, feed, fuels, and chemicals precursors for making higher value products ${ }^{1}$. Carbohydrates such as cellulose and hemicellulose present in plant cell wall are depolymerized to simple sugars using chemical treatment and biological conversions such as enzyme hydrolysis and microbial fermentation². Common pretreatments include Ammonia Fiber Expansion (AFEX), Dilute Acid (DA), Ionic Liquid (IL) and Steam Explosion (SE) that use a combination of chemical and heat to reduce lignocellulosic biomass recalciatrance by opening-up the plant cell wall ${ }^{3-5}$. 
Enzyme hydrolyses are carried out at high solids loading (18\%) using commercial enzymes containing Carbohydrate-Active Enzymes (CAZymes) and microbial fermentation using genetically modified yeast or bacteria to produced biobased fuels and chemicals ${ }^{6}$.

The CAZymes in commercial enzymes consist of complex mixtures of enzymes that synergistically break down the complex carbohydrate sugar linkages yielding simple sugars ${ }^{2,7}$. A complex network of aromatic polymer lignin with carbohydrates makes them highly recalcitrant resulting in incomplete sugar conversion accumulating $15-25 \%$ of unprouctive oligomeric sugars during enzyme hydrolysis of pretreated biomass as we reported before. ${ }^{8}$ This is a universal problem when using different biomass pretreatment methods ${ }^{9}$. Some of the reasons for this bottleneck include enzyme inhibition during hydrolysis or absence or low levels of critical essential enzymes that are necessary to break down sugar linkages in plant biomass ${ }^{10}$. Understanding the sugar composition and structural features such as sugar linkages present in oligosacciardes will help us to improve the sugar conversion during hydrolysis making biobased process cost competitive with petroleum derived products.

Determining the structure of carbohydrates is challenging and are carried out using combination of several techniques such as liquid chromatography (LC) ${ }^{11,12}$, nuclear magnetic resonance specrroscopy $(N M R)^{13}$, capilary electrophoresis $(C E)^{14-16}$, and mass spectrometry $(M S)^{17,18}$. MS technique such as matrix-assisted laser desorption ionization time-of-flight mass spectrometry (MALDI-TOF-MS) provides a versatile method used to identify carbohydrate structures ${ }^{19}$. More recently collision-induced dissociation (CID) tandem MS of sodium ion adduct has been most widely used to determine fingerprints corresponding to linkage positions, anomeric configurations, sequences, and branch locations of oligosaccharides 20,21 .

Glycome profiling is an outstanding tool for intensive identification of carbohydrates linkages ${ }^{22}$. This method uses plant cell wall glycan-directed monoclonal antibodies (mAbs) as probes to understand the complex carbohydrate linkages ${ }^{23}$. More than 250 mAbs are available worldwide that are raised against different linear and branched oligosaccharides with different sugars ${ }^{24}$. Several mAbs has been extensively used to characterize plant cell wall structure, composition, and modifications since there is significant variation depending on the cell types, organs, age, developmental stage, and growth environment of the plants ${ }^{25,26}$. Recently this technique has been used to understand the vesicle populations in plant and animal systems and their respective roles in glycan transport defined by subcellular markers, developmental stages, or environmental stimuli conditions, ${ }^{27}$ and determining enzyme activities ${ }^{28}$. Some of the diverse glycans and xylan structures that have been identified include Pectins (P), Xylans (X), Mannans (M), Xylo-Glucans (XylGs), Mixed-Linkage Glucans (MLG), Arabino-Xylan (ArbX), Galactomannan Glycans (GalG), Glucurono-Aarabino-Xylans (GArbX) and Arabino-Galactan $(\operatorname{ArbG})^{29}$.

With all these research efforts, however, only a few studies have focused on the nature of oligosaccharide buildup during High Solids Loading (HSL) hydrolysis in terms of release of oligomeric sugars, changes in 
the oligomer chain length during the course of hydrolysis, ratios of different DP oligomers and their distribution profiles ${ }^{30-32}$. Meanwhile, even though glycome profiling has been proved to be a useful tool for comprehensive glycan structure analysis, small DP water-soluble oligosaccharides were difficult to estimate using antibody method. Smaller DP oligosaccharides with molecular weight $<15,000$ were not able to bind to the ELISA plates, and were washed away before antibodies were added.

We present here, for the first time, a one-step biotinylating procedure for soluble recalcitrant oligosaccharides followed by glycome profiling using ELISA assay on Avidin-coated plates using mAbs. Complementary oligosaccharide linkage analysis using MALDI-TOF-MS and GC-MS based composition of hydrolyzed sugars using trimethylsilyl (TMS) derivatization corroborate our glycome profiling method. This innovative approach could be developed as a high throughput methodology in the future and used more broadly in biomedical research ${ }^{33}$.

Post-translational modification of enzyme and antibodies such as glycosylation ${ }^{34}$ influence their biological activity. For example, changes in serum protein glycosylation play an important role in inflammatory arthritis and glycosylation changes are used as markers for diagnosis ${ }^{35}$. In literature different glycans are reported to have a high propensity of occurring in various diseases including chronic inflammatory gastrointestinal and liver diseases, viral infection, ovarian, breast and prostate cancer ${ }^{36-38}$. Understanding the glycan structures using glycan directed antibody based ELISA method will provide additional layer of assuredness in disease diagnosis without the need of using sophisticated MS techniques.

\section{Results And Discussion}

\section{Recalcitrant oligosaccharides are a common problem for complete enzymatic hydrolysis of}

lignocellulose. Our previous study found that recalcitrant oligosaccharides remained unhydrolyzed after pretreatment and enzymatic hydrolysis (Fig. 1). A solid-phase extraction method employing activated charcoal was developed to separate oligosaccharides from ACS hydrolysate (ACSH) ${ }^{8}$. After the initial extraction and separation, oligosaccharides were further fractionated by Size Exclusion Chromatography (SEC) and collected in the order of molecular weight. Sugar monomers and oligomers released by different pretreatments were analyzed by sugar composition analysis. By comparing the sugar oligomer content resulting from different pretreatment methods, the existence of recalcitrant oligosaccharides is a common problem in biomass conversion to monomeric sugars and can cause at least $10-15 \%$ sugar yield loss, and even up to $18 \%$ in the case of ACSH.

ELISA-based mAb screening of biotinylated oligosaccharides. Glycome profiling has been proven to be a useful tool for comprehensive glycan structure analysis on extracts isolated from solid biomass residues. However, water-soluble sugars were underrepresented using this routine method ${ }^{39}$, as the small molecule oligosaccharides were challenging to be immobilize on the ELISA plates and were washed away before antibodies were added. Thus, a novel immunological method was developed to enable the coating of soluble recalcitrant oligosaccharides on the Avidin-coated ELISA Plates, enabling the binding with 
antibody and characterization. One-step biotinylation was used to enhance the binding affinity of oligosaccharides (Fig. 2), by adding biotin-LC-hydrazide to the reducing ends of carbohydrates ${ }^{40}$. In solution, the hemi-acetal group at the reducing end reacted with the hydrazide group of biotin-LChydrazide to form a hydrazone linkage. In the presence of the reductant $\mathrm{NaCNBH}_{3}$, the hydrazone linkage was reduced to become a stable biotinylated end-product. With the sugar reducing end modified, the binding of low-DP oligosaccharides to ELISA plates was then possible and was performed on Avidincoated plates with glycan-directed mAbs in our study.

The Avidin-coated plates with oligosaccharides binding were then submitted to primary and secondary antibody addition and wash in a light sensitive and time sensitive environment. After the antibody binding was completed, TMB substrate was added to incubate the plates. Finally, the reaction was terminated by sulfuric acid. The incubated plates were analyzed using ELISA reader to determine the binding intensity for each antibody and hence probing against antibody-specific cross-linkages.

Recalcitrant oligosaccharides epitopes being detected using cell wall glycan-directed mAbs. We proved the value of this newly developed technique in a specific application by characterization of soluble oligosaccharides present in ACSH and in crude and purified oligosaccharides fractions separated from lignocellulosic hydrolysates. As shown in Fig. 3, the most abundant epitopes identified in ACSH using the bionylated glycome profiling method are substituted xylan are usually by uronic acid (U) or methyl uronic acid (MeU) and pectic arabinogalactan. Most of these were also identified in our previous glycomeprofiling studies on unhydrolyzed solids $(\mathrm{UHS})^{41}$.

These non-cellulosic structures cannot be digested by the most abundant cellulases and hemicellulases in commercial enzyme cocktails. Their hydrolysis therefore requires novel accessory enzymes. Without the needed non-cellulosic accessory enzymes, these non-cellulosic linkages hinder complete conversion to monomeric sugars, even though their parent sugar polymers were extensively hydrolyzed into shorter fragments and solubilized using commercial enzyme cocktails.

Further examining the distribution of signals and their binding intensity, we observe that the binding epitopes were more prominent in high DP sugar fractions $(A, B, C)$ than in low DP fractions (D, E, F) (Fig. 1). The acidic fractions were more abundant in non-cellulosic epitopes than neutral fractions. These phenomena were consistent with the patterns observed in our previous study ${ }^{8}$, in which high DP and acidic fractions were more resistant to enzyme hydrolysis. Thus, the existence of non-cellulosic glycan epitopes and $\mathrm{U}$ and $\mathrm{MeU}$ substitutions might contribute significantly to oligosaccharide recalcitrance.

The use of structure-specific antibodies has thus identified the types of recalcitrant linkages. Based on the types of antibody being employed, the corresponding linkage pattern and their intensity (most and least abundant), new enzymes can be identified and added into enzyme cocktails semi-quantitatively for a more complete sugar conversion. Using ACSH oligosaccharides profiling as an example, we can generate a database of glycan linkages for each biomass material. These recalcitrant linkages can then relate to the CAZyme data base, from which we can identify enzymes, select candidates, and screen 
enzymes to break the bonds, or develop microbial system to express these enzymes for use in a biorefinery ${ }^{42}$.

Glycosyl-residue Composition Analyses of Recalcitrant Oligosaccharides. To evaluate how immunological methods can complement alternative characterization methods for low molecular weight oligosaccharides present in lignocellulosic hydrolysates, we performed MALDI (Fig. 4, S1-S8) and GC-MS based TMS derivatized sugar analysis (Fig. 5) on the same sets of oligosaccharide fractions. MALDI was used to compare whether the mass distribution of oligosaccharides molecules fit the hypothesized structure. Fig. 4 shows the MS of neutral fraction ACN-A and ACN-B. Analyses of ACN-A confirmed Pentose series up to 22, the mass of which corresponded with MeU-Xylan oligosaccharides. Analyses of ACN-B confirmed pentose and gluco-xylan series with DP 8-15. In supplementary materials, e.g., Fig. S3, the mass distribution profile of acidic fraction FA-C revealed a $(\mathrm{Me}) \mathrm{U}$ substituted pentose series with DP 8-15, which was consistent the substituted xylan epitope detected in ELISA based mAb screening.

Another interesting finding comes from the LC-MS analysis of the oligosaccharides fractions as shown in Fig. S9 (Methods can be seen in Electronic Supplementary Materials). Fragments of hexose and -OAc groups are repeatedly observed in ACN-B fraction linkages. This finding not only confirms the fragmentation observed in glycome profiling and MALDI-TOF, but also provides new information on potential carbohydrate derivatives in the pretreated lignocellulosic biomass.

We also performed sugar composition analysis of oligosaccharides fractions using TMS sugar derivatization. Using GC-MS, we determined the composition of both neural (non-derivative) and acidic sugars (GluA and GalA) in oligosaccharide fractions (Fig. 5). Gluronic acid was only found in acidic fraction $C$ and $D$ while galacturonic acid was found only in acid fraction $A$ and $B$, which were all high-DP acidic sugar fractions. These results not only support our ELISA and MALDI data, but also are consistent with our previous study. Thus, we are confident that an advanced immunological method using oligosaccharides biotinylation and subsequent ELISA screening was adequate to identify soluble recalcitrant oligosaccharides in different biological samples.

\section{Using commercial oligosaccharides to determine the detection range of glycan-directed mAbs. As the} ELISA-based mAb screening method has been verified by several different methods, we wanted to further explore the potential of this novel method for quantification. Two commercial oligosaccharides, xylohexaose oligosaccharide (XHE) and $2^{3}$-a-L-arabinofuranosyl-xylotriose (A2XX), were purchased and tested using the novel cell wall glycan-directed mAbs method. Fig. 6 shows the linear correlation between the biotinylated binding signal and the logarithm concentration of oligosaccharides concentration, indicating a possible Langmuir adsorption model. Among the mAbs, CCRC-M137, CCRC-M138, CCRCM147, CCRC-M148 and CCRC-M151 showed correlation against XHE, and CCRC-M108, CCRC-M109 and LM11 showed correlation against $A 2 X X$ in the range of $1 \mathrm{~nm}$ to $100 \mathrm{~nm}$.

\section{Conclusion}


Glycome profiling (or ELISA-based mAb screening) is a powerful tool for in-depth characterization of most major glycans constituting plant cell wall. Classical glycome profiling, however, only facilitates characterization of larger cell wall glycans, because most oligosaccharides are not efficiently immobilized on ELISA plates. In this study, AFEX pretreated corn stover was subjected to enzymatic hydrolysis at high solids loading to generate enzymatic hydrolysate. Glycome profiling was employed to determine the composition of recalcitant cell wall carbohydrates in the hydrolysate. However, analysis of smaller oligosaccharides with molecular weight $<15,000$ in the hydrolysate using $m A b s$, was underpresented and requiring additional tools for efficint binding of oligosarrachides to ELISA plates.

We report here a novel and efficient method to successfully immobilize oligosaccharides for ELISA screening, by combining oligosaccharide biotinylation and subsequent $\mathrm{mAb}$ binding and characterization on NeutrAvidin ${ }^{\mathrm{TM}}$ coated plates. The coated biotinylated oligosaccharides showed great affinity for the antibodies, enabling rapid and efficient detection of recalcitrant oligosaccharides. Mass spectrometry based composition analysis of these recalcitrant oligosaccharides further confirmed the results from this novel immuno-screening method. These studies thus demonstrate that combining oligosaccharide biotinylation and ELISA-based mAb screening is useful in identifying and characterizing the crosslinkages in oligosaccharides. This novel method might be widely applied to other biochemical studies characterizing oligosaccharide structures.

This biotin-based glycome profiling method is the first report to enable probing carbohydrate linkages of soluble oligomeric sugars. This method fills an important gap in glycome profiling technology and extends its application to a broader spectrum of substrates other than plant oligosaccharides. In the future, we can use robot to perform biotinylation and analyze the samples using ELISA in a highthroughput fashion to scale up the methods we developed in this study.

\section{Materials And Methods}

Biomass. Corn Stover (CS) grown from Pioneer hybrid seed variety 33A14 was harvested in 2010 from Kramer farm in Wray, CO. Permission was obtained from the land owner to use this biomass for research and the study on the respective plant was carried out in accordance to relevant guidelines. The samples were stored dry $<6 \%$ moisture in zip-lock bags in room temperature. Composition analysis was performed using the NREL protocol ${ }^{43}$. The composition was found to have $31.4 \%$ glucan, $18.7 \%$ xylan, $3.3 \%$ arabinan, $1.2 \%$ galactan, $2.2 \%$ acetyl, $14.3 \%$ lignin, $1.7 \%$ protein, and $13.4 \%$ ash.

Chemicals and Enzymes. Cellic® CTec2 (138 mg protein/mL, batch number VCNI 0001) is a complex blend of cellulase ezymes, b-glucosidase and Cellic ${ }^{\circledR} \mathrm{HTec} 2(157 \mathrm{mg}$ protein/mL, batch number VHN00001) is a complex blend of hemicellulase enzymes were generously provided by Novozymes (Franklinton, NC, USA). Multifect Pectinase ${ }^{\circledR}(72 \mathrm{mg}$ protein $/ \mathrm{mL}$ ) is a comlex mixture of pectine degrading enzymes was a gift from DuPont Industrial Biosciences (Palo Alto, CA, USA). The protein concentrations of the enzymes were determined by estimating the protein (and subtracting the nonprotein nitrogen contribution) using the Kjeldahl nitrogen analysis method (AOAC Method 2001.11 by Dairy One 
Cooperative Inc., Ithaca, NY, USA). Celite 545 was purchased from EMD Millipore (Billerica, MA). Activated charcoal (DARCO, 100 mesh particle), Avicel (PH-101), beechwood xylan and all other chemicals were purchased from Sigma-Aldrich (St. Louis, MO).

AFEX pretreatment. AFEX pretreatment was performed at the GLBRC (Biomass Conversion Research Laboratory, MSU, Lansing, MI, USA). Pretreatmet was carried out at $140{ }^{\circ} \mathrm{C}$ for $15 \mathrm{~min}$. residence time at $60 \%$ (wt/wt) moisture with 1:1 anhydrous ammonia to biomass loading in a bench-top stainless steel batch reac-tor (Parr Instruments Company) ${ }^{44}$. It took $30 \mathrm{~min}$. for the reactor to reach $140{ }^{\circ} \mathrm{C}$ and the ammonia was rapidly released, which quickly brought the biomass to room temperature. The AFEXpretreated corn stover (ACS) composition was similar to UT-CS.

Enzymatic hydrolysis. Enzymatic hydrolysis was performed in duplicate using baffled Erlenmeyer flasks. The AFEX pretreated corn stover was loaded at $20 \%$ dry solids in a fed-batch manner. Half of the biomass was loaded at $\mathrm{t}=0 \mathrm{~h}$, and the remaining biomass was loaded at $\mathrm{t}=45 \mathrm{~min}$. Commercial enzymes Cellic ${ }^{\circledR}$ CTec2, Cellic $® \mathrm{HTec}$, and Multifect Pectinase were loaded at 10, 5, and $5 \mathrm{mg}$ protein/g glucan at $\mathrm{t}=0 \mathrm{~h}$, respectively. Flasks were incubated using a New Brunswick Innova 44 R (Eppendorf, CT) shaking incubator set at $250 \mathrm{rpm}$ and $50^{\circ} \mathrm{C}$ and sampled at different time period.

Biomass Analysis. Extractive-based compositional analyses of the biomass samples were performed according to the NREL Laboratory Analytical Procedures: Preparation of samples for compositional analysis (NREL/TP-510-42620) and determination of structural carbohydrates and lignin in biomass (NREL/TP-510-42618) ${ }^{45}$.

Oligosaccharide analysis. Oligomeric sugar analysis was conducted on the hydrolysate liquid streams using an autoclave-based acid hydrolysis method at a $2 \mathrm{~mL}$ scale. Hydrolysate samples were mixed with $69.7 \mathrm{~mL}$ of $72 \%$ sulfuric acid in $10 \mathrm{~mL}$ screw-cap culture tubes and incubated in a $121^{\circ} \mathrm{C}$ bench-top hot plate for 1 hour, cooled on ice and filtered into High Performance Liquid Chromatography (HPLC) vials. The concentration of oligomeric sugar was determined by subtracting the monomeric sugar concentration of the non-hydrolyzed samples from the total sugar concentration of the acid hydrolyzed samples.

Analytical Method. Glucose, xylose and arabinose concentrations in acid hydrolyzed biomass were analyzed using a Shimadzu HPLC system equipped with a Bio-Rad Aminex HPX-87H column equipped with automatic sampler, column heater, isocratic pump, and refractive index detector. The column was maintained at $50{ }^{\circ} \mathrm{C}$ and eluted with $5 \mathrm{mM} \mathrm{H}_{2} \mathrm{SO}_{4}$ in water at $0.6 \mathrm{~mL} / \mathrm{min}$. flowrate.

Liquid and solid composition analysis. The hydrolysate supernatants were diluted and analyzed for monomeric and oligomeric sugar contents. Monomeric sugars produced after enzyme hydrolysis were analyzed using an HPLC equipped with a Bio-Rad (Hercules, CA) Aminex HPX-87P column and de-ashing guard column. Column temperature was held at $80^{\circ} \mathrm{C}$ and water was used as the mobile phase flowing 
at $0.6 \mathrm{~mL} / \mathrm{min}$. Oligomeric sugars were determined via dilute acid hydrolysis at $121^{\circ} \mathrm{C}$ according to the method reported in the literature $39,46,47$.

Glycome profiling. Glycome profiling of untreated, AFEX-pretreated and all unhydrolyzed biomass residues (involving preparation of sequential cell wall extracts and their mAb screenings) were carried out using the procedures previously described $27,41,48,49$. To conduct glycome profiling, alcohol insoluble residue of plant cell wall materials were prepared from biomass residues and were subjected to sequential extractions with increasingly harsh reagents such as ammonium oxalate $(50 \mathrm{mM})$, sodium carbonate ( $50 \mathrm{mM}$ with sodium borodeutiride at $0.5 \% \mathrm{w} / \mathrm{v}), \mathrm{KOH}(1 \mathrm{M}$ and $4 \mathrm{M}$, both containing sodium borodeutiride at $1 \% \mathrm{~W} / \mathrm{v}$ ) and acidic chlorite as described previously ${ }^{50-52}$. The extracts were then subjected to ELISA against a comprehensive suite of cell wall glycan-directed mAbs ${ }^{48}$ and the mAb binding responses were represented as heat maps. Plant cell wall glycan-directed mAbs were purchased from laboratory stocks (CCRC, JIM and MAC series).

One-step biotinylation of oligosaccharides. The coupling of carbohydrates to biotin-LC-hydrazide was carried using the following procedure. Biotin-LC-hydrazide $(4.6 \mathrm{mg} / 12 \mathrm{mmol})$ was dissolved in dimethyl sulfoxide (DMSO, $70 \mathrm{ml}$ ) by vigorous mixing and heating at $65^{\circ} \mathrm{C}$ for 1 minute. Glacial acetic acid (30 ml) was added, and the mixture was poured onto sodium cyanoborohydride $(6.4 \mathrm{mg} / 100 \mathrm{mmol})$, which dissolved completely after heating at $65^{\circ} \mathrm{C}$ for approximately $1 \mathrm{~min}$. Then 5 to $8 \mathrm{ml}$ of the reaction mixture was added to the dried oligosaccharides $(1-100 \mathrm{nmol})$ to obtain a 10-fold or greater molar excess of label over reducing ends. The reaction was carried out at $65^{\circ} \mathrm{C}$ for $2 \mathrm{~h}$, after which the samples were purified immediately. In labeling experiments without reduction, sodium cyanoborohydride was omitted and the samples were allowed to react at $65^{\circ} \mathrm{C}$ for $2.5 \mathrm{~h}$.

ELISA of biotinylated oligosaccharides samples coating and wash. A $25 \mathrm{~mL}$ of biotinylated sample (100 $\mathrm{mL}$ each concentrated sample diluted in $5 \mathrm{~mL} 0.1 \mathrm{M}$ Tris Buffered Saline (TBS) separately) were added to respective wells on Avidin-coated plates. The control wells were coated with $50 \mathrm{ml}$ biotin at $10 \mathrm{mg} / \mathrm{mL}$ in $0.1 \mathrm{M}$ TBS. DI water was used as coat for blank readings. The plates were incubated at room temperature for $2 \mathrm{~h}$ in the dark. The plates was washed 3 times with $0.1 \%$ skimmed milk in $0.1 \mathrm{M}$ TBS using plate washing program \#11 for Grenier flat 3A.

Primary antibody addition and wash. A $40 \mathrm{ml}$ primary antibody was added to respective wells. The microplates were incated at room temperature for 1 hour in the dark. The plates were then washed 3 times with $0.1 \%$ milk in $0.1 \mathrm{M}$ TBS using plate washing program \#11 for Grenier flat $3 \mathrm{~A}$.

Secondary antibody addition and wash. A $50 \mathrm{ml}$ Mouse/Rat secondary antibody was aded to respective wells (dilute secondary antibody in 1:5000 proportion using $0.1 \%$ milk in $0.1 \mathrm{M}$ TBS). The microplates was incubated at room temperature for $1 \mathrm{~h}$ in the dark. Then the microplates was washed 5 times using $0.1 \%$ milk in $0.1 \mathrm{M}$ TBS using plate washing program \#12 for Grenier flat 5A. 
Substrate Addition. A $50 \mathrm{ml}$ of 3,3',5,5'-Tetramethylbenzidine (TMB) was added to the substrate substrate (Prepare TMB substrate by adding 2 drops of buffer, 3 drops of TMB, 2 drops of hydrogen peroxide in 15 $\mathrm{mL}$ DI Water and vortex before use). The microplates was incubated at room temperature for $30 \mathrm{~min}$. in the dark.

Termination step and reading the plate. A $50 \mathrm{ml}$ of $1 \mathrm{~N}$ sulfuric acid was added to each well and the absorbance was recorded using ELISA reader between 450-655 $\mathrm{nm}$.

\section{TMS sugar composition analysis}

A $1 \mathrm{mg} / \mathrm{mL}$ solutions of these analytes was prepared in deionized water: arabinose, rhamnose, fucose, xylose, galacturonic acid (GalA), glucuronic acid (GlcA), mannose, glucose, galactose, $\mathrm{N}$ acetylmannosamine (manNAc), N-acetyl-glucosamine (glcNAc), N-acetyl-galactosamine (galNAc), myoinositol (internal standard). Two standards were prepared by addding the $1 \mathrm{mg} / \mathrm{mL}$ sugar solutions as Table 1. The samples were frozen at $-80^{\circ} \mathrm{C}$ and lyophilize until all water is removed (usually it takes about 12 - $18 \mathrm{~h}$ ).

Table 1: Standard TMS mix preparation.

\begin{tabular}{|ll|}
\hline Std TMS 1 & Std TMS 2 \\
\hline $50 \mathrm{~mL}$ arabinose & $50 \mathrm{~mL}$ rhamnose \\
\hline $50 \mathrm{~mL}$ fucose & $50 \mathrm{~mL}$ xylose \\
\hline $50 \mathrm{~mL}$ galA & $50 \mathrm{~mL}$ glcA \\
\hline $50 \mathrm{~mL}$ glucose & $50 \mathrm{~mL}$ mannose \\
\hline $50 \mathrm{~mL}$ glcNAc & $50 \mathrm{~mL}$ galactose \\
\hline $50 \mathrm{mLmanNAc}$ & $50 \mathrm{~mL}$ galNAc \\
\hline $20 \mathrm{~mL}$ inositol & $20 \mathrm{~mL}$ inositol \\
\hline
\end{tabular}

TMS Sample preparation. A 100-500 mg of sample was added into a screw cap tube on analytical balance. Record the amount added. It is best to have the samples dissolved in solvent at certain concentration, added into the tube as liquid aliquots. A $20 \mathrm{~mL}$ of $1 \mathrm{mg} / \mathrm{mL}$ myo-inositol was used as internal standard into each sample tube. The amount of internal standard added to sample must be the same as that added into the standard tube.

Preparation of $1 \mathrm{M}$ methanolic $\mathrm{HCl}$ (to perform up to 20 tubes) A $8 \mathrm{~mL}$ of anhydrous methanol was added into a screw cap test tube. A $4 \mathrm{~mL}$ of $3 \mathrm{~N}$ methanolic $\mathrm{HCl}$ was then added and cap was placed and Vortex. No water used in this process. 
Hydrolysis. A $500 \mathrm{~mL} 1 \mathrm{M}$ methanolic $\mathrm{HCl}$ was added into oligosaccharideds sample and standard TMS tubes. The samples was incubate overnight $(168 \mathrm{~h})$ at $80^{\circ} \mathrm{C}$ in heat block. Methanolysis product was dried at room temperature using the drying manifold. A $200 \mathrm{~mL} \mathrm{MeOH}$ was added and dried again. The process was repeated for two times. A $200 \mathrm{~mL}$ methanol, $100 \mathrm{~mL}$ pyridine, and $100 \mathrm{~mL}$ acetic anhydride was added to the sample and mixed well. The sample was incubated at room temperature for $30 \mathrm{~min}$. and dried. A $200 \mathrm{~mL}$ methanol was added and dried again.

Silylation. A $200 \mathrm{~mL}$ Tri-Sil was added and the capped tubes were heated for $20 \mathrm{~min}$. at $80^{\circ} \mathrm{C}$ and then cooled to room temperature. The samples were further dried using drying manifold to a volume of $\sim 50$ $\mathrm{mL}$. It is important to note that we did not allow the sample to completely dry.

Gas Chromatography (GC) samples preparation and injection (Table 2). A $2 \mathrm{~mL}$ hexane was added and mix well by vortexing. Pasteur pipette tip $(5-8 \mathrm{~mm}$ ) was pack a bit of glass wool by inserting the glass wool from the top of 5-3/4 -inch pipette. The samples were centrifuged at 3,000 $\mathrm{xg}$ for $2 \mathrm{~min}$. to precipitate any insoluble residue. The samples were dried until it reached 100-150 mL. About $1 \mu \mathrm{l}$ volume was injected into the GC-MS with initial temp $80^{\circ} \mathrm{C}$ and initial time $2.0 \mathrm{~min}$.

Table 2: GC oven temperature program

\begin{tabular}{|llll|}
\hline No. & Rate & Final temp & Hold time \\
\hline 1. & $20^{\circ} \mathrm{C} / \mathrm{min}$ & $140^{\circ} \mathrm{C}$ & $2 \mathrm{~min}$ \\
\hline 2. & $2{ }^{\circ} \mathrm{C} / \mathrm{min}$ & $200^{\circ} \mathrm{C}$ & $0 \mathrm{~min}$ \\
\hline 3. & $30^{\circ} \mathrm{C} / \mathrm{min}$ & $250^{\circ} \mathrm{C}$ & $5 \mathrm{~min}$ \\
\hline
\end{tabular}

Calculation. If running standards for first time, perform TMS derivatization of each sugar separately and run them individually to procure the profiles of retention times, spectra, and distributions of peaks for each monosaccharide. These profiles will be used to identify the monosaccharide in standards mixture and samples. From the GC-MS, obtain the peak area and retention time of each sugar in standards and samples. Assign the corresponding sugar identities to the unknown peaks in samples according to the standards retention time. Because each sugar can have as many as 4 peaks, in total all the area from peaks corresponding to 1 sugar. Calculate the detector response factor (RF) value of each sugar in the standard mixture against internal standard (in this case, inositol).

For example:

$R F$ of glucose $=\frac{\text { total peak areas of glucose or inositol in standard }}{\text { glucose or inositol weight in standard }}$

Glucose mass in standard is $50 \mathrm{mg}$ if $50 \mathrm{~mL}$ of $1 \mathrm{mg} / \mathrm{mL}$ glucose was added into standard tube. Inositol mass in standard is $20 \mathrm{mg}$ if $20 \mathrm{~mL}$ of $1 \mathrm{mg} / \mathrm{mL}$ inositol was added into standard tube. 
Calculate the mass of each sugar in your sample in mg using the RF value for corresponding sugar. For example:

$$
\text { glucose amount }(\mathrm{ug})=\frac{\text { sample glucose peak area } * \text { inositol mass in sample }}{\text { RF of glucose } * \text { samples inositol peak area Inositol }}
$$

mass in sample is $20 \mathrm{mg}$ if $20 \mathrm{~mL}$ of $1 \mathrm{mg} / \mathrm{mL}$ inositol was added to the sample.

Calculate the mol\% of each sugar Calculate the number of moles of each sugar in sample.

$$
\text { No. of umoles }=\frac{\text { mass of sugar }(\text { in ug })}{\text { MW of sugar }\left(\text { in } \frac{u g}{u m o l}\right)}
$$

MW $=$ molecular weight (e.g., MW of glucose $=180.16 \mathrm{~g} / \mathrm{mol})$. Calculate the total $\mu$ moles of all the sugars present in the samples. Calculate the mol\% of each sugar per total moles of all sugars. For example:

$\%$ sugar composition $=\frac{\text { sugar amount }(u g)}{\text { sample amount }(\mathrm{ug})}$

\section{Declarations}

\section{Acknowledgements}

We express our sincere appreciation to Ms. Christa Gunawan who helped us to perform high solid loading enzyme hydrolysis and composition analysis. We also acknowledge Mr. Lee Alexander for purifying recalcitrant oligosaccharide from high solid loading hydrolysate and for carrying out HPLC analysis for this work. We thank Juan Castro for doing literature search as a part of his capstone project. The research was also supported by the Office of Biological and Environmental Research, Office of Science, United States, Department of Energy through DOE Great Lakes Bioenergy Research Center (GLBRC) Grant DE-FC02-07ER64494 and through BioEnergy Science Center administered by Oak Ridge National Laboratory and funded by a grant (DE-AC05-000R22725). The authors also acknowledge University of Houston High Priority Area Research Seed Grants and the State of Texas for startup funds to VB, and ADJ acknowledges support from Michigan AgBioResearch through the USDA National Institute of Food and Agriculture, Hatch project number MICL02474.

\section{Author contributions}

BD secured funds from GLBRC to perform the work. SX performed the experiments, analyzed the data, made the figures, and drafted the manuscript. VB, LDCS, SP designed the study and protocol. DJ supported and instructed the LC-MS experiment and analysis. BU assisted in writing the article and making figures. All authors critically reviewed the article and approved the final manuscript.

Competing Interests: The authors declare no competing interests. 


\section{References}

1. Isikgor, F. \& Remzi Becer, C. Lignocellulosic biomass: a sustainable platform for the production of bio-based chemicals and polymers. Royal Society of Chemistry. 6, 4497-4559 (2015).

2. Champreda, V. et al. Designing cellulolytic enzyme systems for biorefinery: From nature to application. Journal of Bioscience and Bioengineering. 128 (6), 637-654 (2019).

3. Silveira, M. et al. Current Pretreatment Technologies for the Development of Cellulosic Ethanol and Biorefineries. CHEMSUSCHEM Reviews. 8, 3366-3390 (2015).

4. Bhutto, A. et al. Insight to progress in pre-treatment of lignocellulosic biomass. Energy. 122, 724-745 (2017).

5. Rezania, S. et al. Different pretreatment technologies of lignocellulosic biomass for bioethanol production: An overview. Energy. 199, 117457 (2020).

6. Chundawat, S. Comparison of analytical methods for rapid \& reliable quantification of plant-based carbohydrates for the quintessential bioenergy educator. BioRxiv.(2020).

7. Chettri, D., Verma, A. \& Verma, A. Innovations in CAZyme gene diversity and its modification for biorefinery applications. Biotechnology Reports. 28, e00525 (2020).

8. Xue, S. et al. Sugar loss and enzyme inhibition due to oligosaccharide accumulation during high solids-loading enzymatic hydrolysis. Biotechnology for Biofuels. 8, 1-14 (2015).

9. Jonsson, L. \& Martin, C. Pretreatment of lignocellulose: Formation of inhibitory by-products and strategies for minimizing their effects. Bioresource Technology. 199, 103-112 (2016).

10. Jeoh, T., Cardona, M. J., Karuna, N., Mudinoor, A. R. \& Nill, J. Mechanistic kinetic models of enzymatic cellulose hydrolysis-A review. Biotechnology and Bioengineering. 114, 1369-1385 (2017).

11. Dotz, V. \& Wuhrer, M. N-glycome signatures in human plasma: associations with physiology and major diseases. FEBS Letters. 593, 2966-2976 (2019).

12. Wuhrer, M., Deelder, A. M. \& Hokke, C. H. Protein glycosylation analysis by liquid chromatographymass spectrometry. J Chromatogr B Anal Technol Biomed Life Sci. 825, 124-133 (2005).

13. Duus, J. O., Gotfredsen, C. H. \& Bock, K. Carbohydrate structural determination by NMR spectroscopy: modern methods and limitations. Chemical Reviews. 100, 4589-4614 (2000).

14. Reyes, C. D. G., Jiang, P., Donohoo, K., Atashi, M. \& Mechref, Y. S. Glycomics and glycoproteomics: Approaches to address isomeric separation of glycans and glycopeptides. Journal of Separation Science. 44, 403-425 (2020).

15. Mechref, Y. \& Novotny, M. V. Glycomic analysis by capillary electrophoresis-mass spectrometry. Mass Spectrom. Reviews. 28, 207-222 (2009).

16. Szabo, Z., Guttman, A., Rejtar, T. \& Karger, B. L. Improved sample preparation method for glycan analysis of glycoproteins by CE-LIF and CE-MS. Electrophoresis. 31, 1389-1395 (2010).

17. Kailemia, M. J., Ruhaak, L. R., Lebrilla, C. B. \& Amster, I. J. Oligosaccharide analysis by mass spectrometry: a review of recent developments. Anal. Chem. 86, 196-212 (2014). 
18. Zaia, J. Mass spectrometry of oligosaccharides. Mass Spectrom. Rev. 23, 161-227 (2004).

19. Naven, T. J. \& Harvey, D. J. Effect of structure on the signal strength of oligosaccharides in matrixassisted laser desorption/ionisation mass spectrometry on time-of-flight and magnetic sector instruments. Rapid Commun. Mass Spectrom. 10, 1361-1366 (1996).

20. Hsu Chen, H., Liew, Y., Huang, C. \& Tsai, S. Simple Method for De Novo Structural Determination of Underivatised Glucose Oligosaccharides. Sci. Rep. 8, 5562 (2018). )Ni, C.

21. Lisacek, F. et al. \& Karlsson, N. Databases and associated tools for glycomics and glycoproteomics in High-throughput glycomics and glycoproteomics methods in molecular biology. Methods in Molecular Biology. 1503, 235-264 (2016).

22. Ruprecht, C. et al. A Glycan Array-Based Assay for the Identification and Characterization of Plant Glycosyltransferases. Angew Chem Int Ed Engl. 59, 12493-12498 (2020).

23. Pattathil, S., Avci, U., Zhang, T., Cardenas, C. \& Hahn, M. Immunological Approaches to Biomass Characterization and Utilization. Frontiers in Bioenginering Biotechnology. 3, 173 (2015).

24. Ruprecht, C. et al. A synthetic glycan microarray enables epitope mapping of plant cell wall glycandirected antibodies. Plant Physiology. 175, 1094-1104 (2017).

25. Knox, J. Revealing the structural and functional diversity of plant cell walls. Curr. Opin. Plant. Biol. 11 (3), 308-313 (2008).

26. Dallabernardina, P. et al. Automated glycan assembly of galactosylated xyloglucan oligosaccharides and their recognition by plant cell wall glycan-directed antibodies. Organic \& Biomolecular Chemistry. 15, 9996-10000 (2017).

27. Wilkop, T. et al. Hybrid Approach Enabling Large-Scale Glycomic Analysis of Post-Golgi Vesicles Reveals a Transport Route for Polysaccharides. The Plant Cell. 31 (3), 627-644 (2019).

28. Walker, J. et al. Determination of glycoside hydrolase specificities during hydrolysis of plant cell walls using glycome profiling. Biotechnology for Biofuels. 10, 31 (2017).

29. Kinnaert, C., Daugaard, M., Nami, F. \& Clausen, M. H. Chemical Synthesis of Oligosaccharides Related to the Cell Walls of Plants and Algae. Chemical Rev. 117, 11337-11405 (2017).

30. Vismeh, R. et al. Profiling of soluble neutral oligosaccharides from treated biomass using solid phase extraction and LC-TOF MS. Carbohydrate Polymers. 94 (2), 791-799 (2013).

31. Bharadwaj, R. et al. Microfluidic Glycosyl Hydrolase Screening for Biomass-to-Biofuel Conversion. Analytical Chemistry. 82 (22), 9513-9520 (2010).

32. Qing, Q. \& Wyman, C. E. Hydrolysis of different chain length xylooliogmers by cellulase and hemicellulase. Bioresource Technology. 102 (2), 1359-1366 (2011).

33. Shubhakar, A. et al. Towards automation of glycomic profiling of complex biological materials. Glycoconjugate Journal. 35 (3), 311-321 (2018).

34. Shajahan, A., Heiss, C., Ishihara, M. \& Azadi, P. Glycomic and glycoproteomic analysis of glycoproteins-a tutorial. Analytical and Bioanalytical Chemistry. 409, 4483-4505 (2017). 
35. Biskup, K. et al. Serum Glycome Profiling: A Biomarker for Diagnosis of Ovarian Cancer. Journal of Proteome Research. 12 (9), 4056-4063 (2013).

36. Verhelst, X. et al. Protein Glycosylation as a Diagnostic and Prognostic Marker of Chronic Inflammatory Gastrointestinal and Liver Diseases. Gastroenterology. 158 (1), 95-110 (2020).

37. Prescher, J. \& Bertozzi, C. Chemical Technologies for Probing Glycans. Cell. 126 (5), 851-854 (2006).

38. Jia, N. et al. The Human Lung Glycome Reveals Novel Glycan Ligands for Influenza A Virus. Scientific Reports. 10 (1), 5320 (2020).

39. Lee, Y., lyer, P. \& Torget, R. Dilute-Acid Hydrolysis of Lignocellulosic Biomass. Recent Progress in Bioconversion of Lignocellulosics. 65, 93-115 (1999).

40. Grün, C. H. et al. One-step biotinylation procedure for carbohydrates to study carbohydrate-protein interactions. Analytical Biochemistry. 354 (1), 54-63 (2006).

41. Gunawan, C. et al. Comprehensive characterization of non-cellulosic recalcitrant cell wall carbohydrates in unhydrolyzed solids from AFEX-pretreated corn stover. Biotechnology for biofuels. 10, 1-14 (2017).

42. Terrapon, N., Lombard, V., Drula, E., Coutinho, P. M. \& Henrissat, B. The CAZy Database/the Carbohydrate-Active Enzyme (CAZy) Database: Principles and Usage Guidelines. A Practical Guide to Using Glycomics Databases pp 117-131.Springer, ISBN: 978-4-431-56454-6.

43. Sluiter, A. et al. \& Crocker D. Determination of Structural Carbohydrates and Lignin in Biomass Laboratory Analytical Procedure (LAP). Technical Report NREL/TP-510-42618, Revised August 2012.

44. Balan, V. et al. : Methods and protocols, Methods in Molecular Biology. In: Mielenz JR, Totowa NJ, editors. Lignocellulosic biomass pretreatment using AFEX, vol. 581. New York:Humana Press; 2009.p. 61-77.

45. Hames, B., Ruiz, R., Scarlata, C., Sluiter, A. \& Sluiter, J. Templeton, D. Preparation of Samples for Compositional Analysis. National Renewable Energy Laboratory. 1, 1-9 (2008).

46. Uppugundla, N. et al. \& Balan, V. A comparative study of ethanol production using dilute acid, ionic liquid and AFEX'M pretreated corn stover. Biotechnology for Biofuels. 7, 72 (2014).

47. Sluiter, A. et al. Determination of Structural Carbohydrates and Lignin in Biomass. National Renewable Energy Laboratory. 1, 1-15 (2008).

48. Pattathil, S., Avci, U., Miller, J. \& Hagn, M. Immunological Approaches to Plant Cell Wall and Biomass Characterization: Glycome Profiling. Biomass Conversion. 908, 61-72 (2012).

49. Pattathil, S., Hahn, M., Dale, B. \& Chundawat, S. Insights into plant cell wall structure, architecture, and integrity using glycome profiling of native and AFEXTM-pre-treated biomass. Journal of Experimental Botany. 66 (14), 4279-4294 (2015).

50. Cornuault, V. et al. Monoclonal antibodies indicate low-abundance links between heteroxylan and other glycans of plant cell walls. Planta. 242, 1321-1334 (2015).

51. DeMartini, J. et al. Application of monoclonal antibodies to investigate plant cell wall deconstruction for biofuels production. Energy \& Environmental Science. 4, 4332-4339 (2011). 
52. Pozzo, T., Higdon, S., Pattathil, S., Hahn, M. \& Bennet, A. Characterization of novel glycosyl hydrolases discovered by cell wall glycan directed monoclonal antibody screening and metagenome analysis of maize aerial root mucilage. PLOS ONE. 13 (9), e0204525 (2018).

\section{Figures}

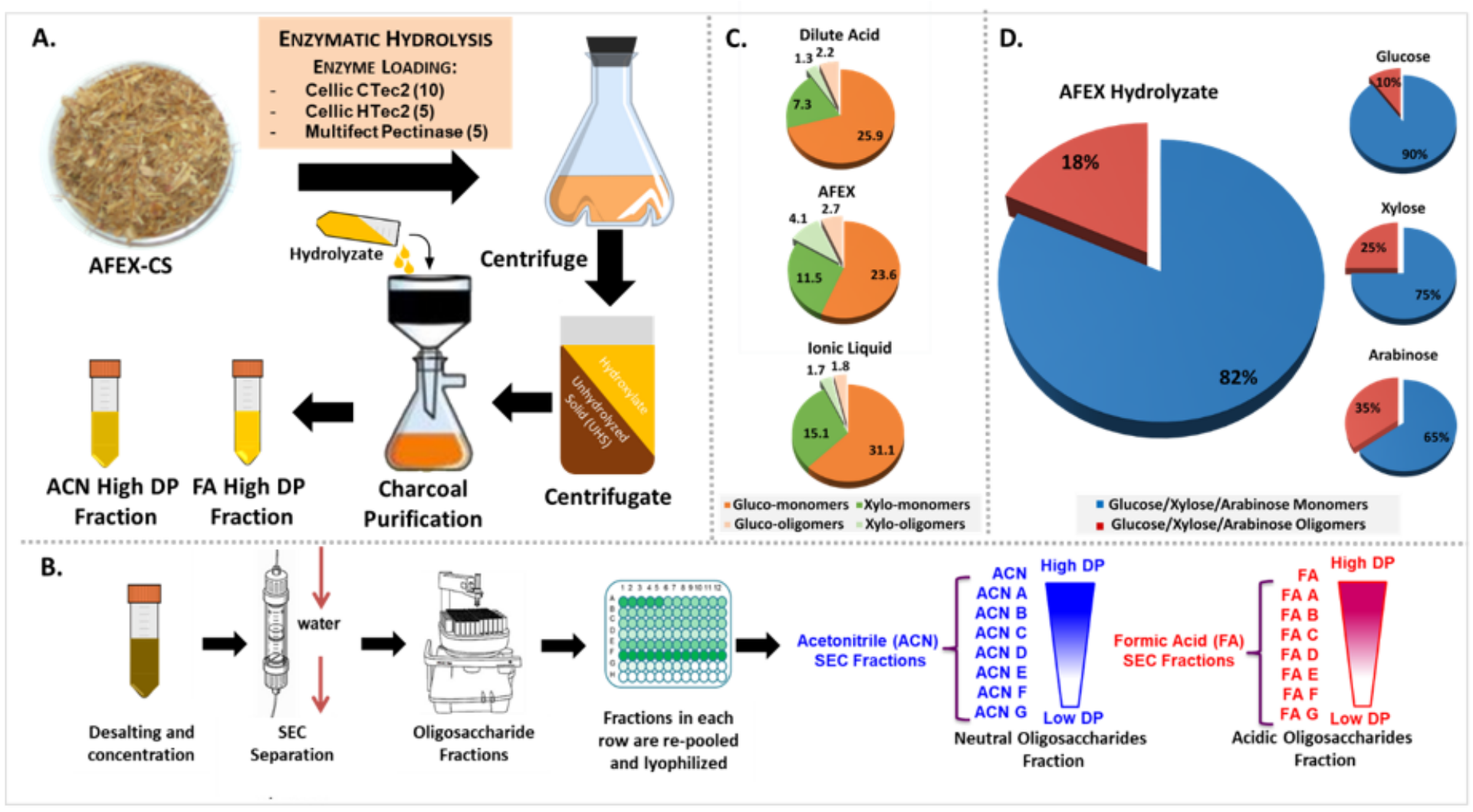

\section{Figure 1}

Recalcitrant oligosaccharides remained unhydrolyzed after pretreatment and enzymatic hydrolysis. Here, A, Methodology of oligosaccharides separation where, oligosaccharides were separated from AFEX-CS Hydrolysate (ACSH) by activated charcoal and celite packed bed; $B$, methodology of oligosaccharides separation. Oligosaccharides were further fractionated by size exclusion chromatography (SEC); $C$, sugar monomers and oligomers released by different pretreatments (dilute acid: DA, ionic liquid: IL and AFEX). Enzymatic hydrolysis conditions: $6 \%$ glucan loading, $72 \mathrm{~h}$ hydrolysis, $15 \mathrm{mg} / \mathrm{g}$ commercial enzyme loading (Ctec2: Htec2: MP - 2:1:1 ratio) and D, Sugar monomers and oligomers of glucose, xylose and arabinose released by ACS. 


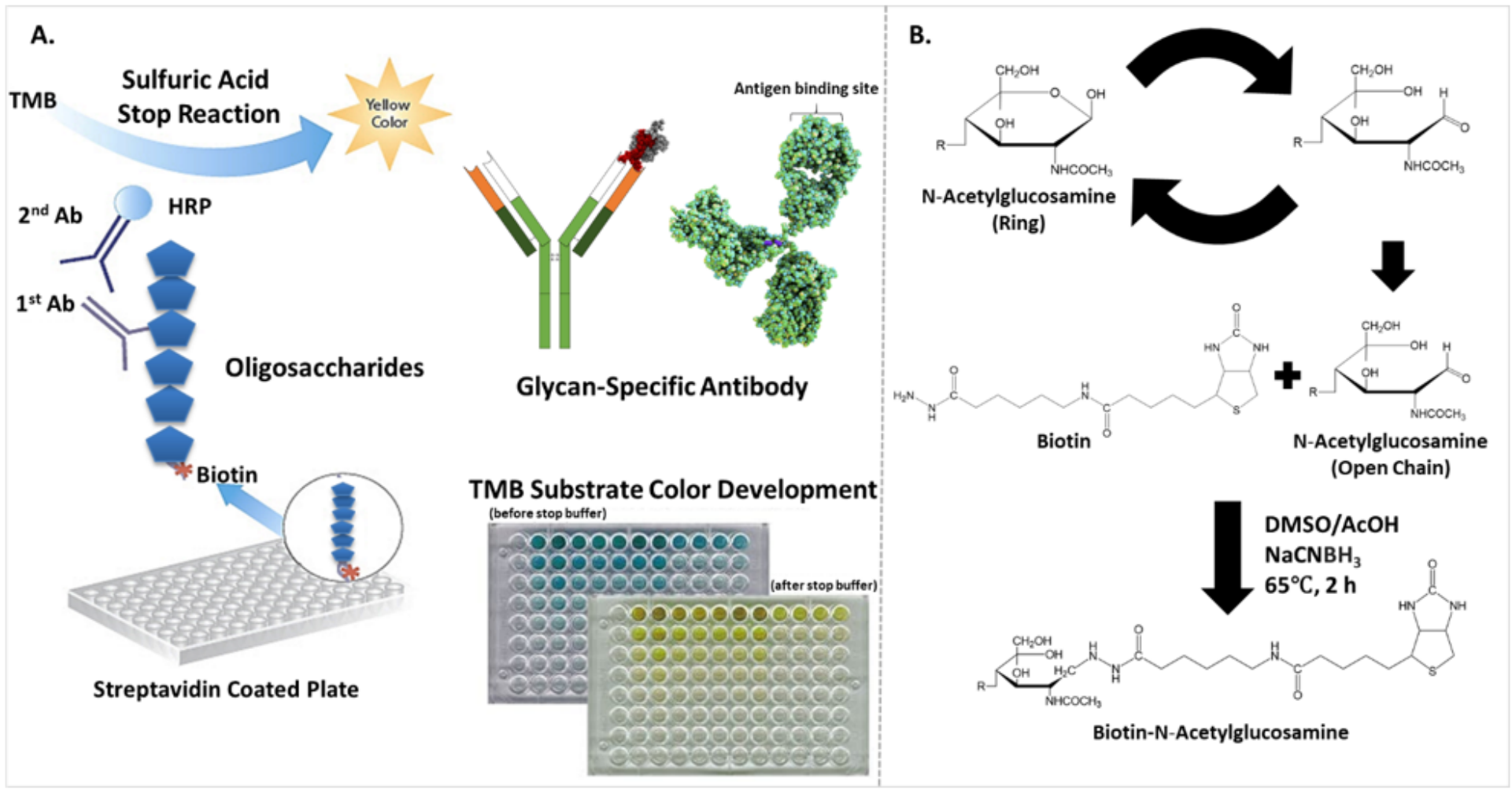

Figure 2

ELISA based monoclonal antibodies screening on biotinylated oligosaccharides. Here, A, combining oligosaccharide biotinylation and subsequent ELISA screening on NeutrAvidinTM coated plates with glycan-directed $\mathrm{mAbs}$ and $\mathrm{B}$, one-step biotinylation procedure showing reaction product. 


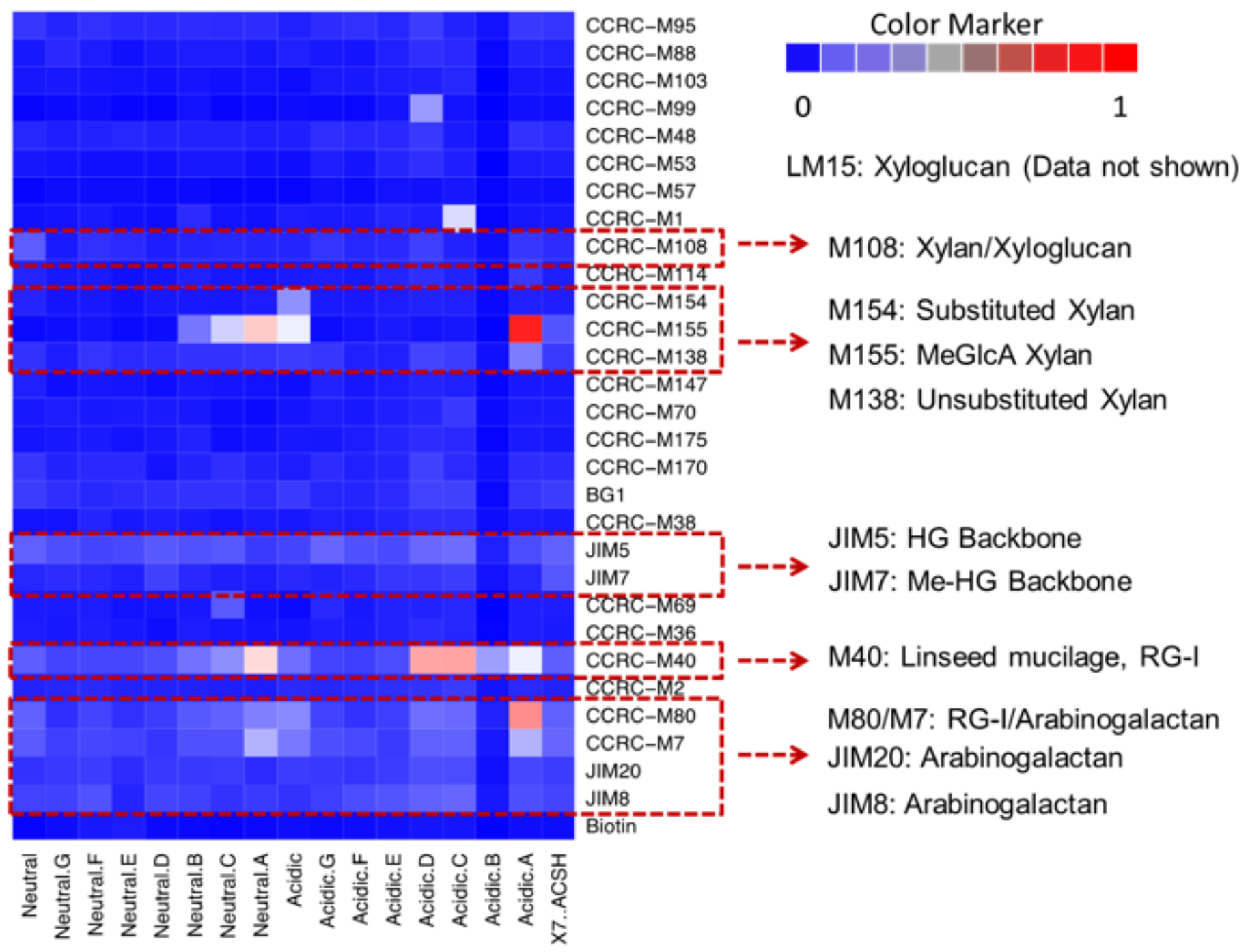

Figure 3

Recalcitrant oligosaccharides epitopes being detected using cell wall glycan-directed monoclonal antibodies. Brighter color indicated abundance of epitope. Different epitopes used the antibodies are given on the righthand side.
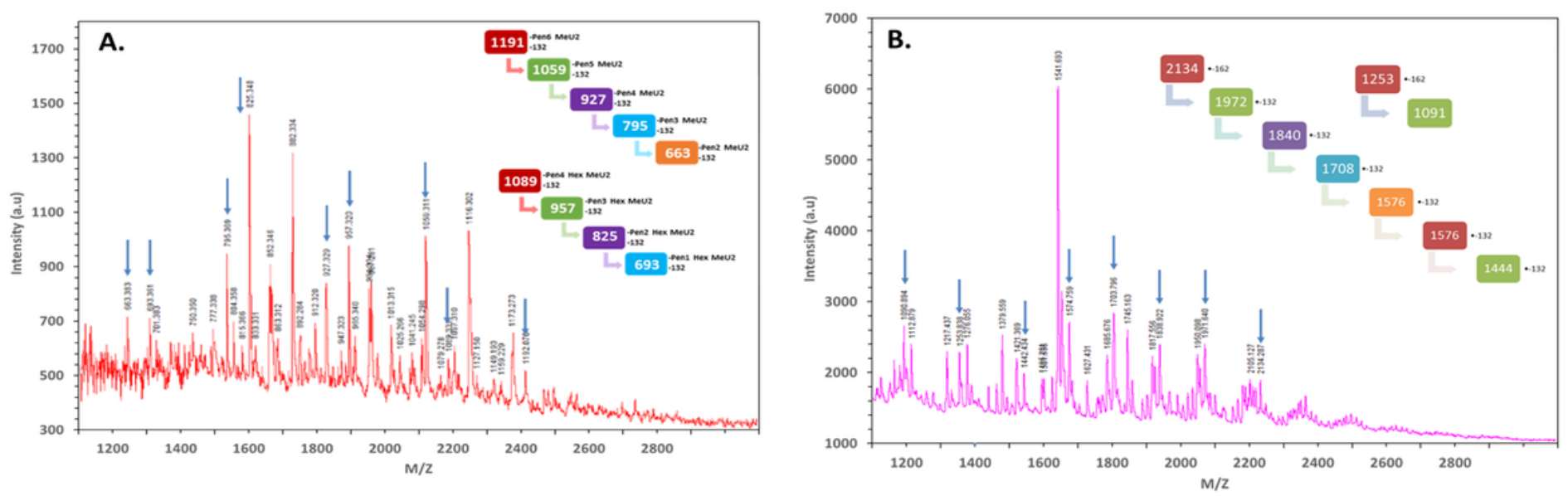

Figure 4 
MALDI-MS spectra of soluble recalcitrant oligosaccharides present in ACS. Here, A, ACN-A fraction containing glucuronoxylan oligosaccharides with methylated uronic acid substitution (DP 22) and B, ACN-B xylan and glucuronoxylan oligosaccharides with methylated uronic acid substitution (DP 8-15).

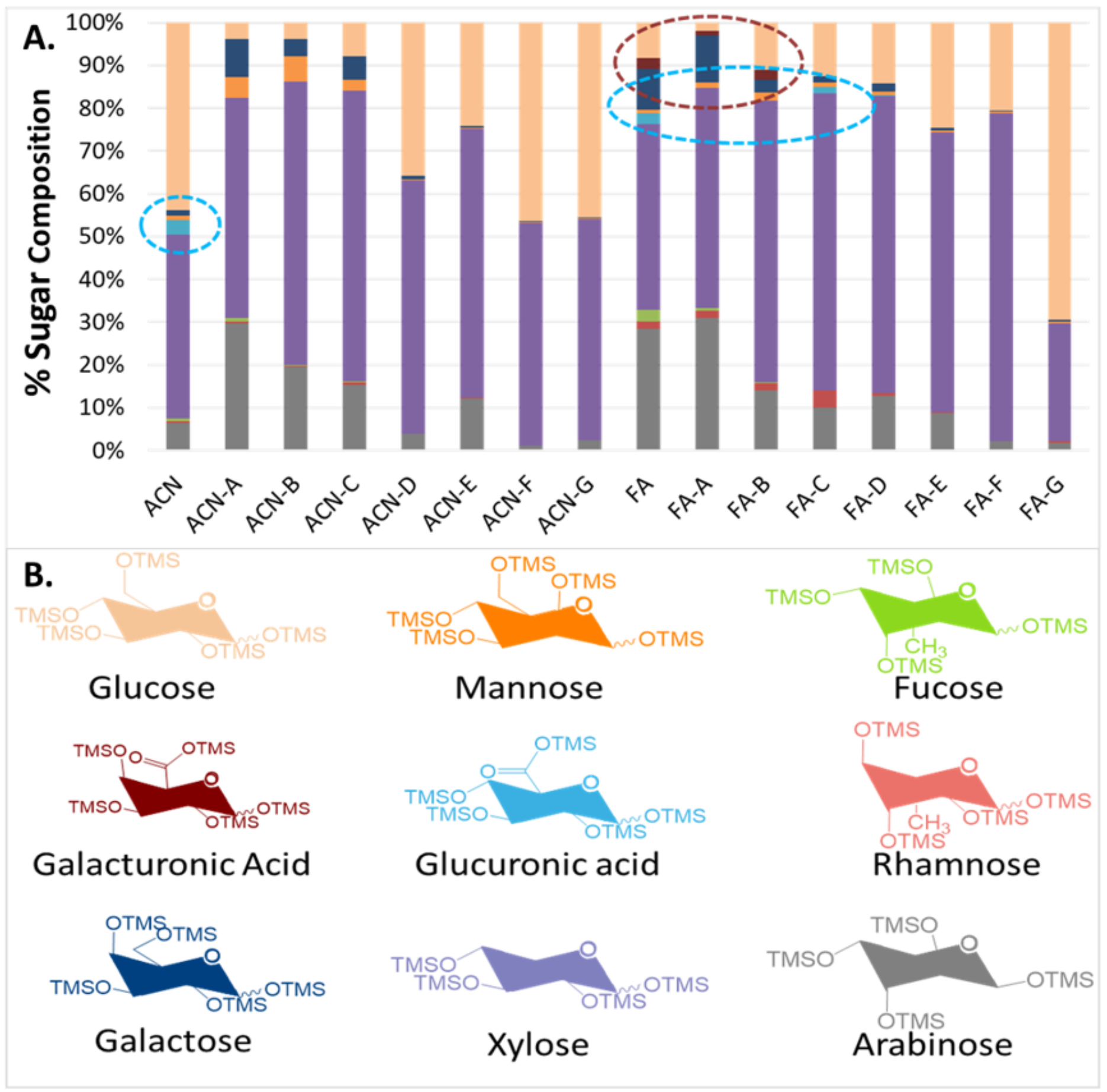

\section{Figure 5}

Glycosyl-residue composition analyses of recalcitrant oligosaccharides. Here, A, TMS sugar composition of different oligosaccharides fractions obtained using GC-MS analysis. and B, Structures of different TMS derivatized sugar present in oligosaccharides. ACN - acetonitrile fraction containing neutral oligosaccharides and FA - Ferulic acid fraction containing acidic oligosaccharides. 


\section{Supplementary Files}

This is a list of supplementary files associated with this preprint. Click to download.

- SRSF.docx

- Additionallnformation.docx 